\title{
The Ideal-Actual Gap in the Roles of Research in Teaching: The Case of STEM Educators in a Philippine University
}

\author{
Bryan Mallillin Nozaleda \\ Cagayan State University
}

Received: March 03, 2020

Revised: April 05, 2021

Accepted: July 19, 2021

\begin{abstract}
The aim of this study is to create an image of how research integrates in university teaching particularly in STEM education in a state university in the Philippines. The participants were 104 teachers from five campuses of the university that offers STEM undergraduate programs. A quantitative research design was employed to address the central theme: The identification of the gap between the beliefs and perceptions of STEM Educators regarding the role of research in university teaching. The present study revealed that the STEM teachers highly valued the role of research in teaching. They especially considered the development of creative and critical dispositions as the most important goals of integrating research into teaching. However, the teachers reported low actual integration of research into their current teaching, revealing a major gap between their beliefs and the perceived actual integration research into their own teaching practices. It further showed that institutional background appeared to be critical in the integration of research in teaching. Ultimately, STEM education in the university is emphatic on research content in the delivery of instruction while creating opportunities for learners to participate along the learning process. However, a research-based approach remains to be unpopular, much less for a research-oriented classroom. Strengthening research support and widening the scope of research culture are recommended.

Keywords: STEM Education, Research-Teaching Nexus, Beliefs and Perceptions, Roles of Research in Teaching
\end{abstract}

(*) Corresponding Author: $\quad$ bnozaleda@gmail.com

How to Cite: Nozaleda, B.M. (2021). The ideal-actual gap in the roles of research in teaching: The case of STEM educators in a Philippine University. Formatif: Jurnal Ilmiah Pendidikan MIPA, 11 (2): 127-138. http://dx.doi.org/10.30998/formatif.v11i2.6182

\section{INTRODUCTION}

In the report of the then Chairperson of the Commission on Higher Education (CHED), Dr. Patricia B. Licuanan on the State of Philippine Higher Education, she stressed one major role of State Universities and Colleges (SUCs) in the country. SUCs must strive in producing high-level academic research and knowledge which are practical and of immediate usefulness. This is no longer new to SUCs, in fact, research as a mission of a university always qualify as a component in quality assurance mechanisms for SUCs. However, research as a core activity of HEIs is notoriously being neglected. Bernardo (2003) has revealed that only 15 out of 223 HEIs in the universities under study were qualified for the graduate-capable HEI category. This observation is supported by a 2016 report on academic research in the Philippines where the country placed 5th among SouthEast Asian Nations below Vietnam and Indonesia. The Philippines is even way below the UNESCO recommendation on Gross Expenditure on Research and Development (GERD) of $1 \%$ of the country GDP. In 2007, the Philippines GERD was less than $0.2 \%$, Indonesia $0.8 \%$, and Vietnam has $0.5 \%$ allocations. These data show that research has not been part of the institutions' history and life. 
On the one hand, in the pursuit of building a research culture, HEI administrators and teachers have to understand that the end of research is not research itself. The products and knowledge generated from research must be utilized for teaching and service. However, tensions exist between universities in both external and internal perspectives on the extent of involvement of teachers and students to research. The Commission on Higher Education has in fact issued a Handbook on Typology, Outcomes-Based Education, and Institutional Sustainability Assessment - a quality assurance tool for universities relative to their typology. This issuance implies a recognition to the struggle for identity of universities across the country. This typology may offer solution to universities, but at the same time, this triggers an increasing expectation on HEIs, as well as the recognition of their significance for a community aimed at building knowledge, and the necessity for the universities to revitalize and reconsider their niche in society and thus their internal organization.

In the Philippines, faculty members are usually working on multi-dimensional roles, comprising of instruction (teaching), research, extension, and production; thus, faculty members in the university are at designated durations of their career performs functions as teachers, researchers, and extensionists. In other words, the strategic career directions of the faculty members are influenced by these roles. In the attempt of describing the role of university teachers, Boyer (1990) identified four areas of the academic profession: the scholarships of discovery, application, integration, and teaching. The latter is to 'study teaching models and practices to achieve optimal learning'. This can be accomplished, for example, by designing and evaluating instructional materials and through application and innovation of learning theories using classroom research. It is interesting that Boyer's report triggered, as observed by Tight (2016), this major research interest in the academic community.

Moreover, the emphasis on the duality of teaching and research is expressed in the differences between teaching in secondary education and in higher education. Two major differences were mentioned in literature. Aside from the conjunction of research function with their teaching function in HEIs, secondary education has the aim of providing general education in contrast with the provision of specialized educative training expected from HEIs. Additionally, it is also observed that most of the teachers in universities have more involvement in research and in a profession but have few pedagogical trainings. Consequently therefore, teachers in HEIs are slanted towards the development of their discipline rather than towards their teaching endeavors. These brought about the ideology in higher education research which relates research and teaching and examine ways that these two elements overlap as a single unit. Academics call this as the research-teaching nexus.

The term research-teaching nexus is used interchangeably with teaching-research nexus, reflecting the importance from the other. This has been the theme of growing discussion in research in higher education. In today's trend, especially in Science, Technology, Engineering, and Mathematics Education (STEM), there is a strong call on bridging the gap between research and teaching. Filling this relation between research and teaching means that HEIs are motivated to rethink and discover ways to adjust in order to prepare for budding changes in the society and the demands introduced by several stakeholders.

In STEM teaching in universities, it is vital to consider knowledge of concepts, theories, and principles in the development of scientific literacy, but teachers must take note that procedural knowledge of scientific inquiry cannot be ignored. The course of scientific inquiry can be accentuated in manifold of ways in the curriculum in which research and teaching are unified. While STEM educators at universities have abundant 
involvement in research and even in teaching, they seldom overtly manifest their leanings to act (Samarapungavan, 2006).

There has been substantial number of papers exploring the relationship of teaching and research, and a variety of ways in which it can be articulated. Similarly, an increasing number of exhaustive, qualitative studies on teachers' perceptions indicated a strong symbiotic relationship between research and teaching. An in-depth reading of these papers suggested the experiences of teachers on research and teaching may be influenced according to the nature of the institution, the academic rank of faculty members, their performance in teaching, the discipline involved, and, above all, the meanings they attach to research and teaching activities.

Conversely, how teachers think about the role of research in teaching is likely to be influenced by what they believe about teaching in general. Brew (2001) has argued that the way in which teachers perceive the nature of research, teaching and knowledge will presumably affect the way in which they bring research and teaching together. Driel and Berry (2012) found that particularly the way in which teachers conceptualize teaching (i.e., their beliefs about teaching) correlates most strongly with the way in which they perceived the relationship between research and teaching.

The way in which teachers embed research into teaching can also be affected by the institutional context. Teachers expedted to be competent to do research and producing inovations in learning (Leonard \& Wibawa, 2020). This is because individual learning, thinking and behavior are assumed to be affected by the structural factors within the institution like resources, workload, evaluation and feedback procedures and institutional policies and other cultural factors within the institution (Smylie, 1995). Marsh and Hattie (1996) has similarly argued that institutional context is likely to mediate the relationship between research and teaching.

However, with the vast plethora of research linking research and teaching, only few studies have delved on discipline specific examination of the link, in STEM in particular. Additionally, since faculty members are expected to be the main producers of research in a university, it would be valuable to determine their beliefs in the role of research in teaching and teaching itself, and their perceptions of the institution's exertions to enhance research efficiency. The beliefs and perceptions of teachers will be examined because they mediate to the knowledge acquisition, definitions of tasks, and actual actions of teachers (Pajares, 1992). Different beliefs and perceptions about the role of research in STEM teaching may thus yield different teaching actions for the integration of research into teaching. These are interesting investigations specially in a university that is in the process of strengthening its research capabilities. Hence, this study.

In this study the beliefs and perceptions of STEM teachers in higher education about the role of research in university STEM teaching are to be examined in connection with hypothesized constraints brought about by their individual and institutional backgrounds. The researcher believes that voices of faculty members must be heard as they contribute to the understanding of an underlying phenomena within a university that is building research culture among its academic forces. This is an attempt to understand the research-teaching nexus in which only few research have actualized in the university.

As an end, the results of this study are deemed beneficial to various sectors in the academic and non-academic community. The study may generate usable information which policy makers in the university can use as basis for program and policy development which concerns teaching and research productivity. Programs that in the end will benefit all academic forces in the university, including teachers and students. Strengthening the research-teaching nexus will eventually produce holistic individuals ready to journey the ever-changing industry or possibly, graduates who can establish their own corporates which will in turn generate jobs and will benefit the community at large. 


\section{METHODS}

\section{Research Design}

This study is guided by a quantitative research design. Specifically, this study employed the descriptive method to carry out successfully the objectives stated in this dissertation. A survey was conducted by the researcher to gather pertinent data and were treated using descriptive and inferential statistics. A survey, according to Scheuren (2004), is a wide-ranging examination, or report of attitudes, opinions, impressions, beliefs, expectations, and behaviors of people on specific facts.

\section{Respondents and Sampling Method}

There was a total of 104 respondents in this study selected on the basis of these criteria: a. Teaching subjects along Science, Technology, Engineering, and Mathematics; and $b$. Have been doing research or those who have done research. The data about the researchers in the university, their number and campus were sourced from the office of the Vice President for Research for Development and Extension.

\section{Research Instrument}

The questionnaire that was used in this study is adapted from a previously validated questionnaire (van der Rijst, Visser-Wijnveen, Verstelle, \& van Driel, 2009; van der Rijst et al., 2013). This questionnaire was also used by $\mathrm{Hu}$ in 2014 in his comparative study of the role of research in teaching as perceived by Dutch and Chinese educators. The main section contained seven scales describing the role of research in teaching. The questionnaire is divided into two: teachers' beliefs about the ideal role of research in teaching and teachers' perceptions of the actual role of research in their own teaching. Items had to be rated on a five-point Likert scale ranging from $1=$ 'always' to $5=$ 'never'.

It is interesting to note that the adaption of this questionnaire is due to the fact that it is re-validated using factor analysis. Hu (2014) carefully chosen those scales which were applicable for probing the role of research in teaching from the prevailing questionnaire and condensed the items by factor analysis, by means of the responses of teachers in a previous transcription from van der Rijst et al. (2013). The concluding seven scales for this segment of the questionnaire were thus: a) developing creative disposition; b) developing critical disposition; c) fostering student research interests; d) enhancing research skills; e) prompting student reflection on research; f) familiarizing students with current research; and $\mathrm{g}$ ) encouraging student participation in research.

Furthermore, although this questionnaire was adapted, the questionnaire underwent content analysis by chosen experts in the field and from a linguistics expert. Interrater reliability was tested to establish reliability of the questionnaire. The questionnaire was also evaluated based on its face validity to ensure that the questionnaire is adaptive to the nature of the respondents.

\section{Analysis of data}

As a protocol to data analysis, prior to the conduct of the formal analysis, normality and linearity of data were checked. Mean and percentage were used to describe the profile of the respondents. The difference between the actual and ideal beliefs of teachers to the role of research was tested using paired T-test and Analysis of Variance (ANOVA) for the profile variables. Pearson- R correlation was used to test relationships. Cohen's D values were computed to describe the degree of difference between the ideal and actual role of research in teaching. 


\section{RESULTS \& DISCUSSION}

\section{Profile of the respondents}

Among 104 respondents surveyed in this study, there is an equal percentage of male (50\%) and female (50\%) faculty-researchers. Meanwhile, in terms of academic rank, majority of the faculty-researchers are holders of Instructor positions (53.8\%) and only $3.8 \%$ or four of the respondents are professors. The disaggregated data on campus and college where the faculty belongs indicates that majority of the respondents are from Carig Campus (32.7\%) followed by Andrews Campus (21.2\%) and Sanchez Mira Campus $(17.3 \%)$. It must be noted that Carig Campus houses the greatest number of faculty members including several STEM undergraduate programs like engineering, industrial technology, and information technology. Moreover, in terms of their highest educational attainment, more than half of the total respondents (59.6\%) are holders of master's degree. Whereas about 40 percent of the respondents are undergraduates and doctorate degree holders. Generally, the average length of doing research by the faculty members surveyed are significantly lesser than the number of years they have been teaching. In fact, the average teaching experience of the 104 respondents is 11 years and for research is 4 years. When the respondents were asked if which is more dominant in their workload- either research or teaching. A negligible $4.8 \%$ answered that there is more research in their workload than teaching.

\section{STEM educators' beliefs and perceptions on the role of research in teaching}

This study is interested in the examination of the beliefs and perceptions of STEM teachers in Cagayan State University concerning the role of research in university teaching, and how these beliefs and perceptions can be elaborated by institutional and individual backgrounds. The concepts of beliefs and perceptions are operationalized in this study following the definition of Pajares (1982). The key terms in this dissertation are used as follows. Teacher beliefs about the role of research in university teaching refer to what teachers believe that research should ideally be integrated into teaching, in short, the ideal role of research in teaching. Teacher perceptions of the role of research in university teaching refer to how teachers perceive the actual integration of research into their current teaching practices and thus the actual role of research in teaching. It must be noted that the role of research in teaching is classified in seven dimensions. The succeeding table presents these dimensions with sample statements in the survey questionnaire. The specific statements on these dimensions and how the respondents rated them are shown in the appended tables.

Table 1. Seven Dimensions of the Role of Research in Teaching

\begin{tabular}{|c|c|}
\hline Role of research in teaching & Sample Statements \\
\hline Creative disposition & foster students' sense of innovation. \\
\hline Critical disposition & $\begin{array}{l}\text { stimulate students not to be easily satisfied with } \\
\text { an explanation. }\end{array}$ \\
\hline $\begin{array}{l}\text { Student research interests } \\
\text { Research skills }\end{array}$ & $\begin{array}{l}\text { encourage students' interest in research. } \\
\text { increase students' ability to conduct research. }\end{array}$ \\
\hline Reflection on research & $\begin{array}{l}\text { stimulate students to learn about research } \\
\text { findings. }\end{array}$ \\
\hline $\begin{array}{l}\text { Current research in the domain } \\
\text { Students as participants }\end{array}$ & $\begin{array}{l}\text { make links to the current research practices. } \\
\text { ask students to make a contribution to research. }\end{array}$ \\
\hline
\end{tabular}


To show a clear illustration on how the teachers' think about the role of research in teaching, Figure 1 summarizes the mean ratings of the seven dimensions of the role of research in teaching. It can be seen from the graph that there is a similar trend on the ideal and actual practice of the respondents in integrating research in their teaching. The role of research in improving the creative disposition of the students received the highest rating. This is an interesting finding since it affirms an apparent teaching practice of teachers in the university particularly for STEM teachers. One of the current academic set-ups in the university is constructivism. In this teaching approach, learners are encouraged to work in groups and discuss on a particular topic. Moreover, students are also encouraged to produce a results-focused proof of the achievement of their learning outcomes. Research helps students think of innovative projects and solutions to ascertain their learning. On the other hand, the least rated role of research is "current research in the domain". This dimension is using research for information transmission particularly on linking current research-based processes in the practice of a profession. This may imply that teaching STEM subjects in the university is focused on the content of the subject matter and current methodologies and processes in the practice of the profession are given lesser attention.

Looking at the same graph, it is interesting to note that in actual practice, STEM Teachers did not rate the role of research in making students direct participants (Students as Participants) in research as high as the other dimensions. This again mirrors the teaching practice in the university where teachers focus on the content in their instruction over the use of research in attaining the learning outcomes.

In general, the beliefs of the STEM teachers on the actual roles of research in teaching were strongly positive and pretty comparable with respect to the ideal role of research in university STEM teaching. There was correspondingly a noticeable agreement on how they ranked the identified dimensions of the role of research in teaching. In both ideal and actual situations, the development of a creative and critical attitude of students ranked highest while creating opportunities for students to link current research practices ranked lowest.

In the local setting, one study conducted by Ulla et al. (2017) examined the perceptions, motivations, challenges, and needs of secondary school teachers in public and private education institutions in Mindanao with regards to doing research. Using a survey questionnaire and an interview as their research methods, the study revealed that although teachers faced various challenges in doing research, they had a positive perception towards it. They believed that through research, their teaching practice would be improved which could have a positive impact on their students' learning.

The result of common beliefs about essence of research in teaching in the university may root from the amplified attention to the conduct of research in the university recently. This is also the observation of $\mathrm{Hu}$ (2016) when he argued that this phenomenon is an aftermath of the apparent academic shifts and trusts, the academic force in a research university are being expected to be involved in research endeavors and assignments (Brew, 2001; Griffioen \& de Jong, 2013; Kyvik \& Skodvin, 2003). Research skill and experience have, moreover, begun to weigh more heavily in the selection procedures for teaching staff (de Jong \& de Jager, 2007). The results of Hu's survey study specified that those efforts also influenced the beliefs about the role which research should plain in the instruction activities of teachers. 


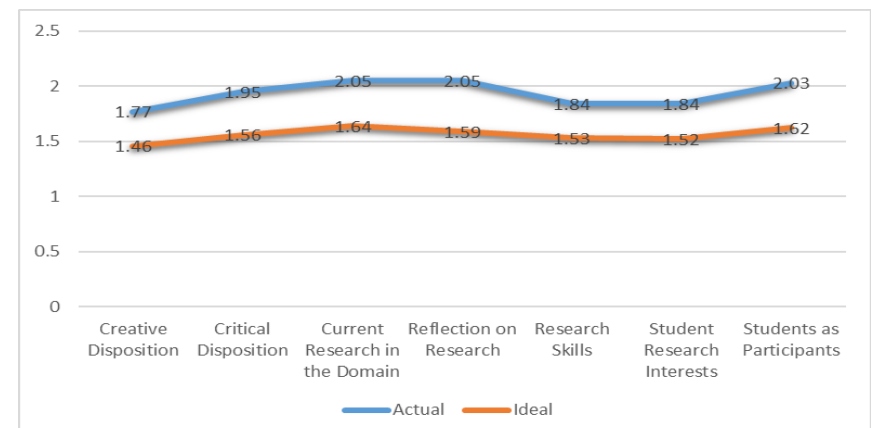

Figure 1. Teachers' Beliefs and Perceptions on the Role of Research in Teaching

To illustrate a clear image of how teachers in the university regard the role of research in teaching in their actual practice, Figure 2 integrates the framework of Healey (2005) and the seven dimensions of the role of research in teaching. The researcher classified the respondents of this study based on the most dominant dimension given by the highest mean rating. Looking at the figure, more than $60 \%$ of STEM teachers in the university are clinging on a research-tutored approach. Healey described this approach where students learn in small group discussions with a teacher about research findings. Interestingly, a quarter of the respondents are clinging on a traditional way of integrating research in teaching. Griffith (2004) termed this as research-led. Students in a research-led learning environment learn about research findings and the curriculum content is dominated by current disciplinary research interests. This means that much of the teaching emphasizes on information transmission. Meanwhile, integrating research processes and problems to teaching and involving the learners as participants or audience received an underwhelming approval from the STEM teachers. A research-based learning environment encourage students to learn as researchers. Also, the curriculum is largely designed around inquiry-based activities, and the division of roles between teacher and student is minimized. Many scholars like Boyer (1990) distinguished the "scholarship of teaching" and just teaching. According to him the purpose of the scholarship of teaching is to "study teaching models and practices to achieve optimal learning'. This can be done, among other things, through developing and testing instructional materials and through advancing learning theory using classroom research.

Consequently, these data can generate meaningful inferences which describe the nexus of research and teaching in the university. These inferences are:

a) STEM education in the university is putting emphasis on research content in the delivery of instruction while creating opportunities for learners to participate along the learning process.

b) Though there is a trend in $21^{\text {st }}$ century education approaches, traditionality of teaching in the university is still evident. A traditional view of the curriculum is still dominant.

c) A research-based approach remains to be unpopular, much less for a researchoriented classroom. Needless to say, STEM teachers do not have a clear understanding of a research-based learning environment and thinks that using research findings during discussion is already an inquiry-based learning. 


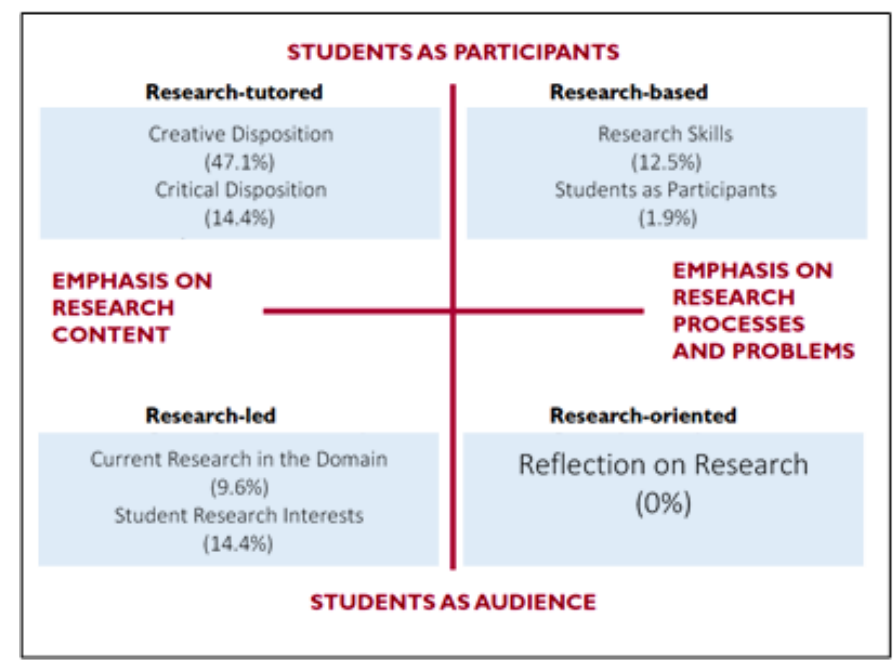

Figure 2. Dimensions of the Role of Research in Teaching woven into Healey's (2005) expression of the research-teaching nexus framework by Griffiths (2004)

As mentioned in the previous section in this chapter, a major gap between the ideal and actual practice of integrating research in teaching was found. For all dimensions, Table 2 indicates medium to large effects and all the test statistics flags significance at 0.01 level. Overall, this means that significant differences in the ideal-actual gap were apparent for all dimensions. This significant gap implies that there is stronger practice of these roles in the ideal situations than what is actually done. Furthermore, this may suggest that there is an existing structural hindrance on the transcendence of the actual to the ideal practice. These factors remain to be identified and can be subject to further studies. Particularly striking in this regard was the gap for the scale "reflection on research" in which the Cohen's d value identifies the gap as "large effect". In this dimension, teachers encourage students to learn more about research findings which are related to their subject matter. Access to updated research findings require an elaborate database of research journals and articles which is primarily served through the internet. E-libraries in the university seems unable to meet the demands of STEM instruction and subscription to scientific research journals may also explain the aforementioned finding.

The actual taken over by the ideal practice is a reflection of the investigation of Neumann (1992). He argued that in an ideal world, teachers believe there should be a strong link between research and teaching. Hu (2014) observed when he compared Dutch and Chinese educators that they share analogous opinions on the ideal practice of research integration. He further deduced that this is an outcome of the increasing stress on research at a global scale. After all, research is believed to be the core of research productivity, and innovation, an important indicator of national competitiveness (Shin, 2012).

Van der rijst (2009) observed too, a substantial gap on teachers' beliefs about the ideal role of research in teaching and perceptions of the actual role of research in teaching between two differently-natured universities. This gap reflects the divergence observed between research and teaching (e.g., Robertson \& Bond, 2001), on a similar note, an almost zero correlation between teaching quality and research productivity (e.g., Hattie \& Marsh, 1996). 
Table 2. Test of Difference on the Perception of Teachers on the Role of Research in Teaching

\begin{tabular}{|c|c|c|c|c|c|}
\hline \multicolumn{6}{|c|}{ Paired Samples Statistics } \\
\hline & & Mean & $\begin{array}{c}\text { Std. } \\
\text { Deviation }\end{array}$ & Sig.Value & Cohen's d \\
\hline Creative & Actual & 1.77 & .60 & $0.000 * *$ & 0.55 \\
\hline Disposition & Ideal & 1.46 & .51 & & \\
\hline \multirow[t]{2}{*}{ Critical Disposition } & Actual & 1.95 & .55 & $0.000 * *$ & 0.77 \\
\hline & Ideal & 1.56 & .46 & & \\
\hline \multirow{2}{*}{$\begin{array}{l}\text { Current Research in } \\
\text { the Domain }\end{array}$} & Actual & 2.05 & .64 & $0.000 * *$ & 0.73 \\
\hline & Ideal & 1.64 & .47 & & \\
\hline Reflection on & Actual & 2.05 & .59 & $0.000 * *$ & 0.91 \\
\hline Research & Ideal & 1.59 & .41 & & \\
\hline \multirow[t]{2}{*}{ Research Skills } & Actual & 1.84 & .59 & $0.000 * *$ & 0.61 \\
\hline & Ideal & 1.53 & .41 & & \\
\hline Student Research & Actual & 1.84 & .54 & $0.000 * *$ & 0.62 \\
\hline Interests & Ideal & 1.52 & .49 & & \\
\hline Students as & Actual & 2.03 & .62 & $0.000 * *$ & 0.77 \\
\hline Participants & Ideal & 1.62 & .43 & & \\
\hline \multicolumn{4}{|c|}{ **significant at 0.01 level } & \multicolumn{2}{|c|}{$\begin{array}{l}\text { Cohen's d interpretation } \\
0.2 \text { to } 0.5=\text { small effect } \\
0.5-0.8=\text { medium effect } \\
0.8 \text { higher = large effect }\end{array}$} \\
\hline
\end{tabular}

\section{Test of Difference on the Roles of Research in Actual Teaching when grouped according to the Profile Variables}

This study also explored if there is any statistically significant difference on the roles of research in actual teaching when grouped according to the profile variables. Table 15 shows that none of the profile variables are significant in differentiating the perception of STEM teachers in the roles of research. This simply suggests that based on profile like academic rank, research experience, and teaching experience, the faculty-researchers have a uniting perception on the roles of research in teaching. As far as available literatures and studies are concerned, there were limited attempts to differentiate teachers' perception on research integration based on profile variables. Hu (2016) managed to differentiate teachers and their perception on the role of research based on length of research experience and the nature of the university where the faculty members are teaching.

However, strikingly, this finding of the present study may divert our attention to a more significant association of research integration. Looking back research culture and research support significantly correlates with the perception of teachers on research roles in teaching. This suggests that improving research support and maintaining a high research culture can change how the teachers perceive the role of research in teaching. Therefore, the attribution of variations in perceptions of the STEM teachers to their profile is not statistically proven as argued in the present study. 


\section{CONCLUSIONS}

The STEM teachers highly valued the role of research in teaching. They especially considered the development of creative and critical dispositions as the most important goals of integrating research into teaching. However, the teachers reported low actual integration of research into their current teaching, revealing a major gap between their beliefs and the perceived actual integration research into their own teaching practices. Secondly, STEM education in the university is putting emphasis on research content in the delivery of instruction while creating opportunities for learners to participate along the learning process. This speaks partly of the STEM teacher's inclination to a student focused/conceptual change belief about teaching in general. However, a research-based approach remains to be unpopular, much less for a research-oriented classroom. STEM teachers remain challenged in understanding an authentic research-based learning environment. Meanwhile, the attribution of variations in perceptions of the STEM teachers to their profile is not statistically significant; hence, none of the profile variables are significant in differentiating the perception of STEM teachers in the roles of research. Research cannot be fully integrated if only the teachers are realizing the importance of research. To build a research culture means involving the students as well. If the university is serious in building a culture of research, it is certainly meaningful that the significance of the of assimilating research into teaching be interwoven in the aims of the institution. The university may consider not only an "outcomes-based" learning outcomes but outcomes which are research-led and research-based. In the event this recommendation be considered, then stern efforts are required to establish this appropriately and deliver the structure and support necessary for such a paradigm shift in education. Furthermore, the researcher also recommends that future investigations guided by a qualitative design exploring both teacher beliefs and practices regarding the research-teaching nexus could contribute to a further understanding of the relationship between research and teaching in STEM education can be initiated. The results may either affirm or negate the findings of the current study. In the present research, a significant gap was found between teacher beliefs about and their perceived actual practices for the integration of research into teaching. An exploration of limiting factors is necessary in the explanation of this phenomenon. Other research has explored the influence of nature of students in the integration of research in teaching. The researcher, therefore, suggests that student factors should also be examined in future research on the integration of research into STEM teaching.

\section{ACKNOWLEDGEMENT}

The researcher would like to acknowledge the assistance extended by the Commission on Higher Education and Cagayan State University in the completion of this study.

\section{REFERENCES}

Bernardo. (2003). in Tullao, T. S. (ed) Education \& globalization (pp. 213-272) Philippine APEC Study Center Network. Retrieved July, 2015 @ http://dirp4.pids.gov.ph/ris/books/pidsbk03-education.pdf

Boyer, E.L. (1990). Scholarship Reconsidered: Priorities of the Professoriate. San Fransisco CA: Jossey-Bass. 
Brew, A. (2001). Conceptions of research: A phenomenographic study. Studies in Higher Education, 26, 271-285.

CHED (2012). Policy-standard to enhance quality assurance (QA) in Philippine Higher Education through an Outcomes-based and typology-based QA. Retrieved from http://www.ched.gov.ph/wp-content/upload /2013/07/CMO-No.46-s2012.pdf

De Jong, H., \& De Jager, G. (2007). Van hogeschool naar kennisorganisatie. Investeren in professionals. THEMA, 7(3), 25-28.

Griffioen, D. M., \& De Jong, U. (2013). Academic drift in Dutch non-university higher education evaluated: A staff perspective. Higher Education Policy, 26(2), 173191.

Griffiths, R. (2004). Knowledge production and the research-teaching nexus: the case of the built environment disciplines. Studies in Higher Education, 29 (6).

Hattie, J., \& Marsh, H.W. (1996). The relationship between research and teaching: A metaanalysis. Review of Educational Research, 66, 507-542.

Healey, M. (2005). Linking research and teaching to benefit student learning. Journal of Geography in Higher Education, 29(2), 183-201. doi: 10.1080/03098260500130387

$\mathrm{Hu}, \mathrm{Y}$. (2014). The role of research in university teaching: a comparison of Chinese and Dutch teachers ( $\mathrm{PhD}$ thesis). Leiden University Graduate School of Teaching (ICLON): Retrieved from http://hdl.handle.net/1887/26834 [Google Scholar]

Kyvik, S., \& Skodvin, O. J. (2003). Research in the non-university higher education sectortensions and dilemmas. Higher Education, 45(2), 203-222.

Leonard \& Wibawa, B. (2020). Development of teacher research competency training system in Indonesia: A need analysis. Universal Journal of Educational Research, 8(5), 2064-2070.

Neumann, R. (1992). Perceptions of the teaching-research nexus: a framework for analysis. Higher Education, 23(2), 159-171. doi: 10.1007/BF00143643

Pajares, M. F. (1992). Teachers' beliefs and educational research: Cleaning up a messy construct. Review of Educational Research, 62(3), 307-332. doi: $10.3102 / 00346543062003307$

Robertson, J., \& Bond, C. H. (2001). Experiences of the relation between teaching and research: what do academics value? Higher Education Research \& Development, 20(1), 5-19.

Samarapungavan, A., Westby, E.L., \& Bodner, G.M. (2006). Contextual epistemic development in science: A comparison of chemistry students and research chemists. Science Education, 90, 468-495.

Scheuren, F. (2004). What is a survey? Alexandria, VA: American Statistical Association. Retrieved from http://www.whatisasurvey.info

Shin, J. C. (2012). Higher education development in Korea: Western university ideas, Confucian tradition, and economic development. Higher education, 64(1), 59-72.

Smylie, M. A. (1995). Teacher learning in the workplace: Implications for school reform. In T. R. Guskey \& M. Huberman (Eds.), New paradigms and practices in professional development (pp. 92-113). New York, NY: Teachers College Press.

Tight, M. (2016). Examining the research/teaching nexus. European Journal of Higher Education, 6(4), 293-311.

Ulla, M. B., Barrera, K. B., \& Acompanado, M. M. (2017). Philippine classroom teachers as researchers: teachers' perceptions, motivations, and challenges. Australian Journal of Teacher Education, 42(11). http://dx.doi.org/10.14221/ajte.2017v42n11.4 
van der Rijst, R. M. (2009). The research-teaching nexus in the sciences: Scientific research dispositions and teaching practice. (Doctoral dissertation), Leiden university, Leiden, the Netherlands. Retrieved https://openaccess.leidenuniv.nl/handle/1887/14011

Van Driel, J. H., \& Berry, A. (2012). Teacher professional development focusing on pedagogical content knowledge. Educational Researcher, 41(1), 26-28.

Visser-Wijnveen, G., J. Van Driel, R. Van der Rijst, N. Verloop, and A. Visser. 2010. "The Ideal Research-Teaching Nexus in the Eyes of Academics: Building Profiles." Higher Education Research and Development, 29 (2): 195-210. 